\title{
THE EFFECTS OF SLEEP DEPRIVATION ON THE JOB PERFORMANCE OF WORKING MOTHERS
}

\author{
Kalpina Kumari ${ }^{1}$ \\ Lecturer at Iqra University, Karachi, \\ Pakistan \\ Sania Usmani ${ }^{2}$ \\ Lecturer at Iqra University, Karachi, \\ Pakistan \\ Siraj Jamal Siddiqui ${ }^{3}$ \\ HOD, Management Sciences at Iqra University, Karachi, \\ Pakistan \\ Javed Husain ${ }^{4}$ \\ Dean, Management Sciences at Iqra University, Karachi, \\ Pakistan
}

\begin{abstract}
Purpose:- Declining work performance is a matter of grave concern for organizations and they make concerted efforts to assess the reasons underlying these loopholes. This research integrates and puts together proofs from the field of psychology and organizational behavior backed by strong neurocognitive evidence while studying the profound effects of sleep deprivation on the performance of working mothers in the educational sector of Pakistan. This research suggests that stress at the workplace partially mediates the negative correlation of sleep deprivation and employee performance.

Methodology/Sample:- Personal survey technique has been applied here as a method of data collection and questionnaire has used as an instrument to collect the data. The sample has been taken from working mothers who are teaching and giving their services in different organizations of educational sector of Pakistan.

Findings:- Based on the findings and hypothesis results it can be concluded that the given negative relationship between sleep deprivation and employee performance is partially mediated by stress at workplace.

Practical Implications:- The results and contribution of present research can be of great importance to the management of all educational sectors operating in Pakistan including schools, colleges and universities. The findings and suggestions of this research could provide them with necessary data to address and resolve the issue related to performance of working mothers who are sleep deprived, due to which they are experiencing stress at workplace, and are deviating from the desired norms of an organization.
\end{abstract}

Keywords: Sleep deprivation, stress at workplace and employee performance.

\footnotetext{
* The material presented by the author does not necessarily portray the viewpoint of the editors and the management of the Institute of Business \& Technology (IBT)

1 Kalpina Kumari

2 Sania Usmani

3 Siraj Jamal Siddiqui

4 Javed Husain

(C) IBT-JBS is published by the Institute of Business and Technology (IBT).

Main Ibrahim Hydri Road, Korangi Creek, Karachi-75190, Pakistan.
} 


\section{PROBLEM BACKGROUND}

Every organization has been established with certain objectives to achieve. Factors of production like man, money and commodity assist the company to achieve the desired result. Labour and human resources are the most vital part out of all these resources. It plays an important role in performing tasks for accomplishing the goals. The way this human resource is managed is of utmost importance. In addition, the corporate environment is undergoing a revolution. The factors that consist of the environment are not within an individual's control. Even the management of organization is unable to control it. In order to excel in the business world it is essential that you have to walk in accordance with the outside environment. External factors like social, cultural, legal, political, economic, technology and competition is undergoing a rapid and drastic change. Hence, it follows that one should keep him/her self updated and aware of these constructs, in order to ensure that his planning is sound. In this fastpaced working environment it is quite a challenge to foresee things in the future. The future is not known to anyone. Thus here, arises the need to employ people who are highly trained and can be relied upon to give maximum yield. Nowadays the markets are also very competitive and have made the business environment a place where it is hard to survive. The challenge of the organization is not only to set its grounds, but also to stay in the market, maintain an equilibrium and progress in the specific field. The human resource of an organization gives it the competitive advantage and differentiates it from the other competitors in terms of the proficiency and dedication. In order to reach the pinnacle of success it is important that all the departments within the organizations work in close association and coordinate the activities with the efficiency and effectiveness.

The nature of the organization determines the type and specificity of the job that the employee performs. They primarily serve in different roles ranging from producing and manufacturing, keeping things in store, transporting material, creating awareness about the product or service, making arrangements for funding and compiling income and expenses, managing the labour and human power, survey and maintaining relations with the public. In order to achieve the desired targets, all the activities are cross-connected within the organization. These are supposed to be performed by the employees properly so they can give their best output at the job. This will have profound effects on the overall net production, sales volumes, development and growth, and the standing of the organization in the market which determines its market share in the long term. Variables like the expertise and talents, mentoring, level of motivation, commitment and dedication for the company, rules and policies of the management, fringe benefits, attractive salary packages, bonuses, climbing up the hierarchy and commuting etc are responsible for raising the morale of the employees, so that they perform their best and work with utmost sincerity. The management should direct concerted efforts towards enhancing the performance of employees, after thoroughly understanding its importance in order to gain the desirable results within the organization. The management has the authority and position to direct and motivate people to maintain a certain level of performance. Finally the company may take the leading position over the competitors and can grab the opportunities promptly which are available in the 
market.

\subsection{Problem Statement and Research Questions}

The study aims to observe the association between sleep deprivation and the performance of working mothers with in the educational sector of Pakistan and to examine the role of "stress at the workplace" within the given relationship of sleep deprivation and performance of working mothers.

The problem as indicated above could be stated as in the following question: What is the relationship between sleep deprivation and individual performance, taken into consideration the role of stress at workplace?

In order to answer the above main question, the following sub questions will first be answered:

1. How sleep deprivation is related to individual performance?

2. Is stress at the workplace performing the role of a mediator with regard

to the relationship between sleep deprivation and individual performance?

\subsection{Objectives and Significance of the Study}

However, the scope and contribution of present research is very vast and beyond the past researches. This research study aims to investigate the relationship between sleep deprivation and individual performance, and to examine the role of mediator, which is "stress at the workplace" in the given relationship of sleep deprivation and individual performance. Thus the objective of present research is to fill the gap in literature and answer the key question about how sleep deprivation can impact on the performance of working mothers of educational sector in Pakistan. Another important question that has been answered in this research paper is that do these working mothers feel anxiety due to being sleep deprived, and can these two factors collectively lead towards poor performance at the workplace.

In the past several decades, researches in the field of sleep is becoming all the more important to organizational scholars, as for the past few decades, the average number of hours, worked on an annual basis throughout the world has increased. it has significantly contributed to an emerging culture, where sleep deprivation is prevalent (national institute for occupational safety and health [niosh], 2004). on the other hand, just like the western countries the trend has become very popular and common in the culture of pakistan that women have started to work in the corporate sector just like men, along with their home responsibilities. being a mother is an essential part of these women's lives and sleep deprivation is an inevitable part of having a baby, thus it has become a matter of grave concern for the management of an organization as how to balance the personal and professional lives of these working mothers in the best possible manner so that the organizational goals can be achievedefficiently and effectively.

Therefore, the objective of this research study as described above is to use a mediation theoretical perspective to highlight the potential consequences of sleep deprivation on performance of working mothers within boundaries of Pakistani 
educational sector. How the impact of these consequences can be managed, has also been focused in this research study so the maximum output can be achieved from the employees (working mothers) within the organizations. In doing so, it has been argued that one critical state underlies the relationship between sleep deprivation and individual performance i.e. stress at workplace.

\section{LITERATURE REVIEW}

It has been researched in past that a minimum of 5 to 6 hours of sleep and the everincreasing demands of modern day professional lives have taken tolls on the personal lives of mothers and their relationships at work. Whereas conclusion of different researches has also proposed that the majority of mothers throughout the world today suffer from chronic sleep deprivation, which affects every area of their lives. Just looking after a baby or young child is enough to bring you to your knees, but most of the mothers also have to meet the complicated demands of their partner, extended family, and employer too. This becomes an uphill task for those mothers who barely get 4 hours of sleeps each night, leaving them frustrated, short-tempered, and highly bitter and irritable. Furthermore, according to a poll, mothers who survive on hardly five hours sleep at night are completely drained by the end of the day in an attempt to balance the contradicting and hectic demands of professional life along with motherhood, where they fail to appreciate the true essence of having the privilege of being a mother. More than a large portion of 56\% said that exhaustion left the mothers in a "condition of despondency"; while, $82 \%$ of working mothers accepted that absence of sleep negatively influenced their work productivity at workplace. Moreover, $61 \%$ of working mothers complained that their manager failed to realize the sensitivity and seriousness of the situation that lead to their tiredness at work; whereas, $88 \%$ were hesitant on resuming back to their daily routine work as they felt saturated, worn out, and "pulled in too many directions". Moreover, 70\% said that their tiredness was so incapacitating that they felt they were "not able to function properly" and were more clumsy and susceptible to committing mistakes. Therefore, women are advised to take complete rest and if needed extend their maternity leave before resuming to their professional life.

On the other hand researchers also proposed that many walks of life face the after math of missing out on important hours of sleep including your school life, work-place activities, commuting, adjusting from one place to another, and socializing. A person will see that his ability to grasp concepts, concentrate, retain and act accordingly will reach low ebb. He may also fail to precisely identify and respond to other people's emotional responses and cues. Being social will seem like an almost impossible feat as he will be undergoing mood fluctuations, keeping him perplexed and unapproachable most of the time. He might not only look all disheveled in the morning after missing out on important hours of sleep or staying up all night, but it will also exhaust his energy reserves and will make him irritable throughout the course of the day. 
The negative effects of sleep deprivation reach as far as affecting people's mood, as they might have experienced themselves. After being sleep deprived for a whole night, one may be more prone to developing an irritable mood, showing intolerant behavior and presenting susceptibility to stress. His mood is significantly affected, even if he is partially sleep deprived, as shown by studies. Subjects who were able to sleep only for 4.5 hours per night every week, were reported to be under a feeling of stress, anger, sadness, and mental exhaustion as studied by the researchers at the University of Pennsylvania. There was a drastic uplift in the mood and anxiety disorder when the subjects were allowed to take their normal amount of sleep and ultimately leading towards increased productivity at workplace. Psychological problems also stem from the inability to sleep properly. Take for instance that acute insomnia puts an individual at a greater risk of being a patient of mood disorders, like depression or feeling of anxiety. It was five times more likely that depressed patients were usually those who suffered from insomnia, as found by an important study carried out on 10,000 adults. The study went on to establish the fact that nervous breakdowns (a classification of anxiety disorders) were also 20 times more common in insomniac patients. All types of anxiety disorders including depression and other psychiatric disorders, traced their origin to insomnia. As reported in Medscape Neurology and Neurosurgery, people who work in night shifts are the most likely victims of stress, both on and off the job. This dilemma goes on to aggravate matters by leading to other anxiety disorders like heart diseases, extreme gloominess, problems related to the stomach, high blood pressure, inefficient immune system, and infertility. To keep oneself stress-free at least for some time it is an absolute necessity that he sleeps sufficiently for a substantial period of time. Conversely, if he is not getting enough sleep, he may offset his hormonal balance that causes stress and set him in the undesirable direction.

The demanding position of being a working mother, Sheila, a Boston district attorney, had to juggle between maintaining a work-life equilibrium and cater to both the requirements of her full-time job and looking after her young children. She started to undergo chronic periods of crankiness, irritability, and unusual depression. When her children were old enough to sleep soundly throughout the night, she felt a considerable change in her mood and the level of exhaustion, as she started getting at least 7-8 hours of sleep on the daily basis.

Moreover, as it is foremost agenda of nearly every kind of organization is the ability to create a workforce, which is efficient and effective and yields the best results. This is all even more important when companies are facing tough competition in the marketplace and they cannot take the risk of anything below that. In order to come out victorious in this highly competitive environment, the first step is to identify the underlying reasons that can impact negatively to the performance of employees at the workplace. There are always some roadblocks that deter an employee for utilizing the resources they are equipped with and perform at their best. This, in turn, negatively affects the employee's performance ultimately. Stress being one of the most important factors. An employee's physical and mental well-being is adversely affected by stress at the workplace, which is why it needs to be precisely identified and addressed. According to Harrold and Wayland (2002) when stress level increases, the motivation level, efficiency, productivity, organizational effectiveness, absenteeism, and general 
prosperity of the organization is negatively affected. Now it's being the responsibility of an organization that in which way they equip themselves in the best possible manner so as to keep stress levels in their organization to a minimum level and improve performance of the employees at the workplace.

However, nowadays, a larger number of people are sleep deprived these days because they require time in order to cope up with the work load and stress that the ever-increasing demands of the modern world has put on them. Simultaneously, people are not realizing the seriousness of the situation, as they are putting themselves at a higher risk of potential harm than they can imagine. These anxiety- stricken people are not only sleep deprived but their sleep patterns are inconsistent and restless as well, leading to decreased work productivity, greater chances of errors in their professional life and accidents that may take a toll on lives as well as resources, as revealed by scientific research.

Recently there might have been fewer cases being reported related to severe accidents occurring due to sleep deficiency. However, that definitely does not mean that the exhaustion and lack of attention due to sleep did not lead to these tragedies. Upon investigation, when the causes for the nuclear accident at Three Mile Island in 1979, along with the nuclear meltdown at Chernobyl in 1986 were studied, inadequate sleep was identified as a major reason for the disasters.

A link between the destruction of the Exxon Valdez oil tanker, as well as the blast of the space shuttle Challenger, and sleep deficit have been established. In both the accidents, culpable negligence was observed on the part of the people responsible for the operations. They were inattentive and distracted due to sleep deprivation and hence they were unable to make the necessary decisions. The multi-billion dollar shuttle program was put at risk by the Challenger disaster, while the Exxon Valdez oil spill left immeasurable disastrous effects on the environment and ecology as well as financial losses was also incurred.

Additionally, lack of sleep has also been deeply linked to the occurrence of medical mishaps in the hospitals besides its effect on life-threatening incidents. Lack of sleep has been found responsible for causing a lot of serious injuries and death. The figure quoted by the Institute of Medicine for the number of deaths due to avoidable medical mistakes as a result of sleep loss is as high as 50,000 to 100,000 deaths annually. Long working hours, of 24 to 36 hours drain the doctors and deprive them of sleep.

It is quite hard to precisely determine the degree to which lack of sleep leads to negatively affecting the performance of medical personnel. Studies carried out in this regard have proven that sleep deprived individuals are more prone to committing medicinal errors. A member of the Division of Sleep Medicine at Harvard Medical School, Dr Charles Czeisler in 2004 concluded in a study that by reducing the working hours of doctors down to 16 hours and keeping 80 hours as the limit for the total working hours per week, the incidence of medical mishaps can be greatly reduced to as low as 36 percent. 
On the other hand, undesirable mood fluctuations, a shorter concentration span and inability to work at our maximum mental capacity are some unconstructive after-effects of sleep loss. Mental performance is hence a comprehensive blend of these traits. In the laboratory, researchers has used scientific procedures to conclude that how considerably varying levels of sleep disorder can impact various forms of mental performance.

As discussed above, the mood and behavior of an individual is drastically affected by sleep deficiency. Victims of acute and consistent sleep deprivation, mainly adults have, reported that they undergo unnecessary mental torture, symptoms of depression, anxiousness, and alcohol abuse (; ; ). Upon the meta-analysis of around 19 original articles, a link between partial sleep deprivation and mood was discovered, which was of a greater intensity as compared to its effect on cognitive or motor functions (). When studies were carried out on more than 30,000 adolescents inclusive of high school students, results show that people are more likely to become victims of acute depression, restlessness, anxiety, mood fluctuations, and alcohol abuse when they are sleep deprived $(; ;)$, and even try to commit suicide (). However, it is an unclear discussion from the cross sectional research that whether sleep deprivation and the mood fluctuations are linked by the cause-effect relationship or vice versa. A survey carried out on 2200 middle school students (aged 11 to 14 years) in a longitudinal study of over 3 years concluded that people were prone to deeper depressive signs and extremely low selfesteem when they self-reported about the sleep loss ().

Now, if one talks about the impact of stressors on job performance and satisfaction, earlier studies reported deleterious and harmful effects of a wide variety of stressors on the swiftness and preciseness of keeping track of things, gauging signals, drawing logical conclusions during conversations, constructing meaningful sentences, and other related forms of performance related to verbal cues and gestures (Lazarus, Deese, \& Osler, 1952; Wilkinson, 1969). Stress has been found to take a toll on individuals and exhaust them, leaving them low on energy (Glass \& Singer, 1972). Cohen's (1980) has released a recent version of model on stress, which proposes that when subject to stress, the brain undergoes high and unbearable processing of information as it demands an individual's complete concentration. Resultantly, intellectual ability is hampered and drains one of the energy to perform on tasks. This model has been reviewed and ascertained through several studies by Cohen (1980). Stress related factors, like rowdiness, electric mishaps, political hypocrisy, and workload in which people tend to show a decline in their ability to perform well on tasks, which demand patience and calmness of mind to tolerate irritation, precision in paperwork, and the art of avoiding distractions based on one's own perception. Their sensitivity towards other people also reduces drastically and they start to display "a decrease in helping, a decrease in the recognition of individual differences, and an increase in aggression" (p. 95).

Ivancevich and Donnelly (1975) went on to study different managerial levels of an organization and established a close association between anxiety, employee performance, and contentment. He concluded, based on finding, that low levels of anxiety and stress ultimately uplift the performance of an individual at work. Beehr, Jex, Stacy, and Murray (2000) laid the foundation of the correlation between the stress factors present in the 
workplace and the resulting performance of the individual. This even has high chances of mental demoralizing to an individual. Jamal (1984) further extended the study by introducing managers and blue-collar employees into the scenario, looking into the relationship between job stress and performance.

The working environment and the organizational culture of the workplace which makes an individual feel insecure, results in job stress. Job stress and performance have been linked with each other in innumerable ways, some of which are: U-shaped and curvilinear, positive linear, negative linear and no relationship between the stress and performance. For investigation purposes, a sample of 325 managerial and 305 bluecollar workers were selected at random in a Canadian firm and were brought under surveillance via structured questionnaires. The variables under study were mainly, level of stress, performance at work, and the level of commitment towards the organization. The relationship between the level of stress experienced on the job and the resulting job performance was found to be negative linear. Moreover, very limited evidence is seen for curvilinear or no association.

Therefore it can be summarized here that different occupations were taken under observation to study the effects of sleep deprivation on employee performance in the past literature and it was concluded that sleep deprivation takes a toll on physical and mental health of employees. Apart from the unpleasant and undesirable effects of lack of sleep on health issues, it has been observed that it results in decline in an individual's performance with greater chances of errors at the workplace. Sleep deprivation can affect the productivity of all working people, be it a truck driver who has to drive long miles or a student who stays up all night to study for his/her exams. If they fall short of sleep, they would not be able to function to their maximum capacity. Thus discoveries from studies that utilized correlative exploration techniques have merged together to firmly propose that deficient sleep quality and quantity are the leading causes of lower productivity at workplace. Employees feel that their ability to maintain their $100 \%$ focus, acquire knowledge, and convey their thoughts show a steep decline because of sleep deprivation, with an increase in the memory lapses. The potential to tackle problems at hand also shows low ebb. The employees tend to take time to get adjust in the new environment and accept other's point of view and hence tend to indulge in conflict of opinion, which makes them more vulnerable to volatile emotional reactions and affects their workplace relations. Attitude of people towards their jobs also shows a decline, which leads to lower job satisfaction at the work place. This, in turn, adversely affects the performance of an organization as a whole. Inadvertently, both professional and personal lives experience the negative impacts of losing out on essential hours of sleep. Furthermore, as nowadays it is not surprising that many people are subject to dilemma of extreme sleep shortage due to the constraints that the demands and time limits of modern around-the-clock society put on them. In this regard, an imperative question is, how our body reacts to stress when we are in a state of utter drowsiness as it helps us to combat difficulties that come our way on a daily basis? Thus the answer to the above given question which has been proposed by different researchers is that an individual may feel lethargic, put off the whole day and tend to fuel up unnecessary arguments and take up a voluntary solitary attitude if he does not get enough rest, doze 
off at inappropriate times or do not sleep soundly. Upon waking up, he will not feel invigorated and cautious. The functioning and activity of the various systems is undermined when an individual is sleep deprived, which adversely affects the alertness of the mind and physical fitness. Therefore, it has also been proved based on past researches that sleep deprivation not only directly effects individual performance but is a major stressor and simultaneously cause employees to indulge in deviant acts in the workplace, reducing overall employee performance and productivity inevitably.

\section{RESEARCH METHODOLOGY}

The process of designing a research effectively forms a specific order through which the findings are considered as valid and repeatable. The way a research is designed relates primarily to making sound decisions regarding the questions under study, modeling the research problem, forming a concrete basis to rest the idea upon, and, employing certain methods in order to obtain and evaluate relevant data (Mouton \& Marais, 1990). The perspective, with which this study has been analyzed, is discussed in this chapter. It presents rationalization for the way the research has been designed (size of the sample, formulation of the questionnaire, carrying out the required survey, description of the instruments used).

\subsection{Population}

That part of the population with which the research group is concerned and which includes the entire set of units relevant to the problem/phenomenon being studied is known as the targeted population (Zikmuand, 2003). The population that has been targeted in this research study is the educational segment of Pakistan. The unit of analysis of this research is defined by this segment taking into account those working mothers who are rendering their services within the educational sector of Pakistan. The educational sector of Pakistani territory has been divided into three categories i.e. schools, colleges, and universities.

\subsection{Sampling Design}

Non probability sampling design was used to select the respondents to be studied. This method of selection is chosen when the researcher intends to ensure that a sufficient number of people are selected for the study with minimum cost being incurred (Black, 1999). Karachi city was made the centre of acquiring samples as it is a metropolitan city and represents citizens from all over Pakistan. Furthermore, quota sampling technique has been implemented from non probability sampling design. Based on rough judgment, in Karachi city there are about nine hundred eighty nine schools, one hundred eighty six colleges and sixty universities. After developing control categories of defined population elements, respondents of the study are being selected based on convenience sampling technique. Thus out of 989 schools, 300 questionnaires have been sent to different 30 schools, out of 186 colleges, 200 questionnaires have been sent to different 20 colleges and out of 60 universities 100 questionnaires have been sent to different 10 universities. 


\subsection{Sample size}

Selecting the sample size of the study was the next logical step after deciding about sampling method. The sample size for this study was decided by using the Raosoft sample size calculator. The method employed functions on the basic principle that increasing the population size has a direct effect on the sample size of the population to some extent after which it achieves stagnancy. After this point altering the size of the population will have no effect on the sample size. Accurate estimation of the target population for this research was not practically possible hence it was assumed to be infinite. However, for calculation purposes an approximate of 20,000 was taken to be the target population's size as a rough estimate. A recommended sample size of 377 , based on above given formula, when margin of error has been fixed as 5\% and confidence interval as 95\%, Comrey and Lee (1992), has also proposed a general rule of the thumb that states that an acceptable number is 300 cases followed by 500 as very good and 1000 as excellent. Hence a sample size of 377 respondents seems fair enough.

\subsection{Instrument}

The instrument used for the measurement of the mediation model of sleep deprivation adopted for the pilot study was found to be reliable and understandable to the respondents. Thus, no further changes were introduced to the instrument used for the pilot study and the same instrument was carried onwards for the main research study.

The survey instrument consists of 19 items among sections, to cover background information of employee's sleep deprivation, the level stress among the employees, and their performance at the workplace. Each item in the questionnaire was measured on a five point's likert scale (apart from sleep deprivation which has been assessed by open-ended question).

Different portions were allocated to different constructs being measured by different instruments, so that the respondents did not get confused. Introducing the concept underlying the study and then giving the necessary instructions in order to completely fill out the questionnaire was covered in the first part. The main variables of the study were analyzed in the second part of the questionnaire and the third part consisted of demographic questions - relating to the name of respondents, age, level of education, educational sector and name of organization in which they are working as it has been explained above as well.

The second part, which has assessed main variables of study, has been divided into further three sub divisions. the first section contains questions about sleep deprivation, the second section contains questions about workplace stress and the third section contains questions about employee performance. 


\subsection{Hypothetical Framework.}

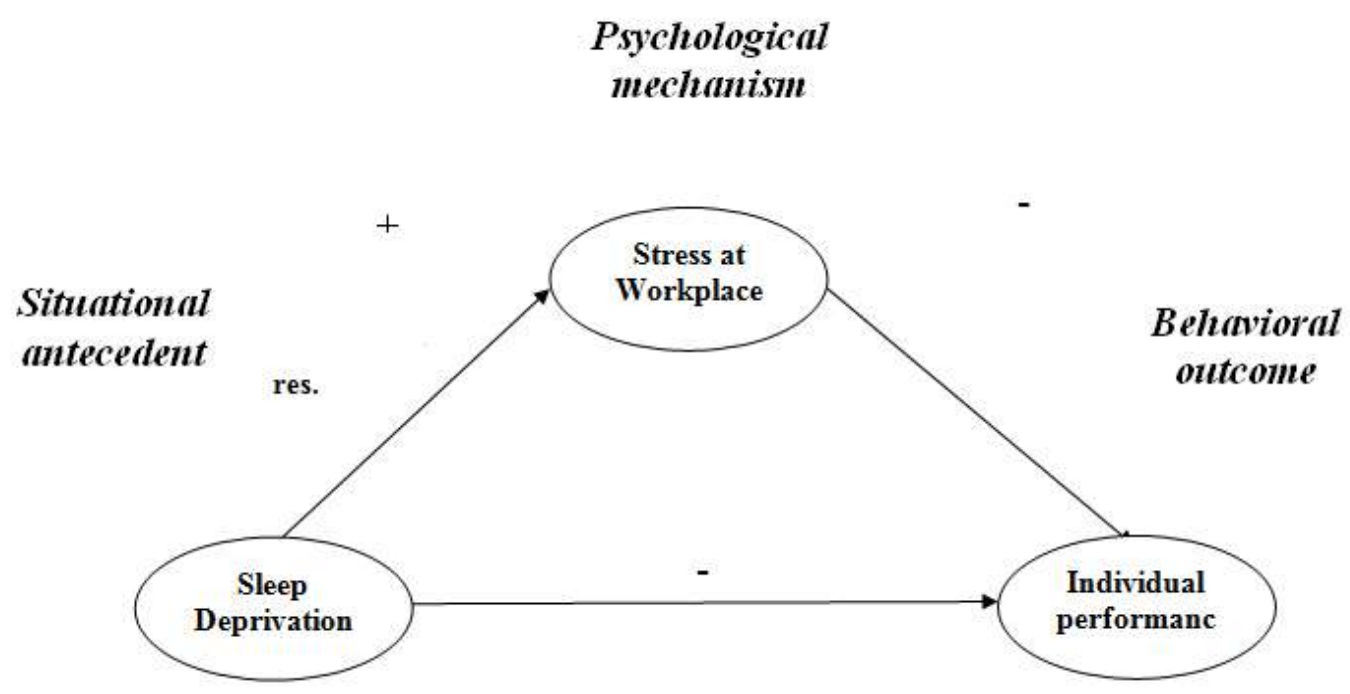

Fig. 3.1: Conceptual framework, leep Deprivation. Keeping the previous researches in mind, the status of a categorical

Variable has been given to partial deprivation (e.g., Barnett \& Cooper, 2008; Chen, Gill, \& Prigerson, 2005; Gangwisch, Malaspina, Boden-Albala, \& Heymsfield, 2005; Kripke, Garfinkel, Wingard, Klauber, \& Marler, 2002). 6 hours was selected as the cutoff point. In order to measure the sleep deprivation, the question was first interrogated from the target population i.e. working mothers as to how many hours they had slept the night before, they took the survey. A code of 1 was given to an individual to label her as sleep deprived, if she had gotten 6 or less hours of sleep and an individual was coded as 0 , indicating no sleep deprivation, if she had slept for 7 hours or more.

\subsubsection{Stress at Workplace}

House and Rizzo (1972) devised a 5-point likert scale containing seven components (questions) along the lines of "strongly disagree" to "strongly agree" and this scale has been employed as an instrument to measure the pivotal role of stress at the workplace in the current study. Examples of items included: "I feel fidgety or nervous as a result of my job" and "I feel nervous before attending meetings in the organization'. The coefficient alpha was reported as 0.83 . 


\subsubsection{Workplace Deviance}

As this paper studied and examined the impact of production deviance quadrant of Robinson and Bennett's typology of workplace which throws light on the possible influence of the production deviance quadrant on individual performance, so this variable (construct) has been assessed by using 7 items of production deviance as per the measures established by Bennett \& Robinson's (2000). Participants have been asked to indicate their judgment on a 5-point likert scale ranging from $1=$ never to $5=$ always in order to signify "how often they had engaged in the deviant behaviors". Items as sample included "I Worked on a personal matter instead of work for my employer," "I came in late to work without permission," "I intentionally worked slower than I could have worked," and "I spent too much time on fantasizing or daydreaming instead of working".

\subsubsection{Individual Performance}

A five-item scale for in-role job performance was adapted to measure individual performance by a Dutch translation (Van Yperen \& De Jong, 1997) of Podsakoff and MacKenzie's (1989). Subjects of the study were expected to give feedback on their degree of agreement or disagreement regarding the five statements as follows: (1) "This worker always completes the du-ties specified in his/her job description," (2) "This worker fulfills all responsibilities required by his/ her job," (3) "This worker often fails to perform essential duties," (4) "This worker never neglects aspects of the job that he/she is obligated to per-form," and (5) "This worker meets all the formal performance requirements of the job." Here the item 3 is reversed. Format of responses ranged from "strongly disagree" (1) to "strongly agree"(5).

\subsection{Procedure}

The current research is probe by questionnaires; whereas method of data collection was personal survey technique. A self-administered questionnaire was developed by combining three separate established instruments measuring every construct separately. A section on demographics was added for gathering information about age, level of education, type of educational sector in which these women are employed such as school, college or university and finally the name of organization in which they are working.

The study's objectives, instructions related to general things, and the very fact that how essential it was to completely fill out the questionnaire for the researcher was personally made clear to the potential respondents in the covering letter attached with each questionnaire.

At random, 300 questionnaires were sent to different 30 schools, 200 to different 20 colleges and 100 to different 10 universities of Karachi via email, fax, and post, and accessible areas were visited personally. After every three days a reminder in the form of an e-mail was sent to every respondent in order to remind them to complete and 
return the filled questionnaire on time.

Afterwards, unprocessed data, which was received from the questionnaires was coded and entered into the software to be statistically analyzed. Three-seventy-seven responses were received in the form of questionnaires, of which 37 responses were unusable. The responses used for analysis were 340 . Thus, the response rate was $62.8 \%$. It is an indirect indication of relevance and rigor of a study in the opinion of the respondents if the response rate is moderate. Respondents are more likely to return a questionnaire if they perceive that the study is important and warrants their cooperation.

\subsection{Statistical Methodology}

In order to examine the mediating effects of stress at workplace between relationship of sleep deprivation and individual performance, bootstrapping method from SPSS which has been proposed by Preacher And Hayes (2008) software has been implemented in this research paper.

\section{RESULTS AND DATA ANALYSIS}

SPSS for Windows Version 14.0 is used as the main tool of data analysis. To begin with, the data was fed into the SPSS sheet, assigned different codes, and then amended in order to carry on further analysis. For the attainment of the unique aims of the research, sample characteristics of the dependent and independent variable were tested upon and analyzed in depth. Furthermore, a diverse range of statistical techniques were employed in order to evaluate the hypotheses that were created in the given research. Before implementation of these diverse statistical techniques, editing was performed to identify the missing values and wrong entries in order to get the substantiate results. For all the variables a comprehensive code book was developed. Study's main variables tapped on 5 point Likert scales that were given the values ranging from 1 to 5 (apart from sleep deprivation which has been assessed by open ended question). Next, for the purpose of data entry all of the study's main variables which are sleep deprivation (1), workplace stress (07), and employee performance (05) were defined in SPSS. Thus, all questionnaires received from relevant respondents were entered into SPSS.

Following data migration, all sorts of data are scrutinized for any misfits or values that seem to be contradicting the rest of the data and may not be accurate. It helped to determine that while transferring data from one source to another source, whether the data was complete, was precisely translated and is compatible to be processed in a new system or not. During verification, there may be a need for a parallel run of both systems to identify areas of disparity and forestall erroneous . Double entry systems and proof reading the work can be classified as data verification. Checking the data entered against an original document by someone is known as proof reading, for the purpose of eliminating any discrepancies. 
To ensure the accuracy of data, following steps were taken after entering all the data into SPSS sheet:

- $\quad$ Frequencies were generated for all the variables in order to check the values to be within the stipulated range of values that was specified in the preparation of codebook. In case of any variable having some unspecified values which are called as "aberrant values", the correction was made by referring to the original questionnaire.

- $\quad 50 \%$ of the total respondents were selected randomly for proofreading and checking for every item entered. Thus, the data entry for 186 participants from 377 was confirmed.

Missing values has been identified by implementing "Missing Values Analysis" in the SPSS software.

\subsection{Mean Standard Deviation and Skewness of All Variables.}

Table 4.1 shows the minimum, maximum, mean, median, standard error of mean, standard deviation, skewness, kurtosis, and mode of all the study variables. All the given descriptive values have been calculated separately for sleep deprived working mothers and for those who are not sleep deprived. However, the values for all variables remain within acceptable ranges (see in Appendix A, Table 4.1).

\subsection{Inter correlation with in Items and within Variables of Study.}

The inter scale correlation matrix Table 4.2 displays correlation coefficient between the variables measured by already established multiple-item scales (see in Appendix A, Table 4.2 ).

The coefficient turns out to be significant if the value of $\mathrm{p}$ turns out to be less than 0.05. Table 4.2 (see in Appendix A) summarizes the results and confirms that there is a strong relationship between the dependent, independent and mediating constructs of this study. All the variables taken into account in this study have a significant relationship with sleep deprivation. Furthermore, the correlation matrix ascertains the fact that workplace deviance and sleep deprivation are positively correlated $(r=.386, p<.01)$, stress at workplace $(\mathrm{r}=.319, \mathrm{p}<.01)$, and inevitably a negative correlation with employee performance $(\mathrm{r}=-.354, \mathrm{p}<.01)$. Also stress at workplace and workplace deviance happen to be positively correlated $(\mathrm{r}=.453, \mathrm{p}<.01)$ and hence having a negative relationship with employee performance $(r=-.475, p<.01)$. Stress at workplace also leads to decreased employee performance hence establishing a negative relationship $(\mathrm{r}=-0430, \mathrm{p}<.01)$.

\subsection{Reliability Analysis.}

Coefficient alpha was applied at the beginning of the study (Cronbach, 1951). Analysis of data was necessary in order to test the reliability of the research. .Combined reliability estimates of all the given constructs were computed in the current study. Homogeneity 
amidst a group of data was represented by a coefficient ranging from 0 to 1 . If the value of alpha happens to be lower than $(a=60)$ it is considered as a poor result whereas greater reliability is achieved if the value is obtained in close proximity to $(a=1.0)$. A coefficient value of at least 0.70 is indicative of good reliability (Hair, Anderson, Tatham, \&Black, 1995; Pallant, 2001). The scales adopted in this study are based on validated instruments. In order to ascertain whether the scales used to measure the dependent and one mediating variable i.e. stress at workplace, and employee performance, are internally consistent or not, the alpha coefficients were calculated (see in Appendix A, Table 4.3).

Cronbach's alpha reliability or inter item consistency reliability coefficients of a dependent, and one mediating variable were obtained. The overall reliability for each scale is given separately in Table 4.3 and the value of the acceptable reliability limit as being defined by Cronbach is should be of more than $(\mathrm{a}>.70)$. Thus conclusion for the reliability of given scales in this particular study was made on the basis of Cronbach's alpha value for each construct. Since the values were even more than $(a=.70)$ hence it was concluded that the measures adopted in the study were internally consistent and reliable.

\subsection{Hypothesis Derived from Mediation Model (see Figure 3.1)}

H1: There is a negative association between sleep deprivation and individual performance.

$\mathrm{H} 2$ : There is a positive relationship between sleep deprivation and stress at workplace.

H3: There is a negative relationship between stress at workplace and employee performance.

H4: Stress at workplace mediates the relationship between sleep deprivation and individual performance.

H5: When stress at workplace is held constant, there is also a direct negative effect of sleep deprivation on individual performance.

\subsection{Results and Interpretations}

H1: There is a negative association between sleep deprivation and individual performance.

Result and Interpretation: $\mathrm{H} 1$ has been accepted as $\mathrm{p}$ value of the total effect shown in Appendix B (see the results of Bootstrapping) is less than 0.05, ( $p=0.0000$, coefficient $=-0.8488$ ). Thus it can be concluded based on given values that sleep deprivation has a negative influence on the performance of working mothers.

$\mathrm{H} 2$ : There is a positive relationship between sleep deprivation and stress at workplace.

Result and Interpretation: Based on the evidence listed in Appendix B (see the results of Bootstrapping), it is clearly shown that there is a significant positive association between sleep deprivation and stress at workplace as the $\mathrm{p}$ value is less than 0.05 , ( $\mathrm{p}$ $=0.0000$, coefficient $=.4060$ ). 
H3: There is a negative relationship between stress at workplace and employee performance.

Result and Interpretation: H3 has also been accepted and proved that there is a negative association between stress at workplace and employee performance as the $\mathrm{p}$ value is less than 0.05, ( $\mathrm{p}=.0000$, coefficient $=-0.4540)$ as shown in the Appendix $\mathrm{B}$ (see the results of Bootstrapping).

H4: Stress at workplace mediates the relationship between sleep deprivation and individual performance.

Result and Interpretation: $\mathrm{H} 4$ has been accepted as from the "Bootstrapping results of Indirect Effects" (see in Appendix A, Table 4.4), it is clearly shown that the indirect effect $\mathrm{a} \times \mathrm{b}$ through the stress at workplace mediator is significant and it means that mediation between the sleep deprivation and employee performance through stress at workplace has been established, as the $95 \%$ confidence interval does not include 0 (.3062 to -.0928 in the case of SW). Since a x b x c (0.0706) is positive, which means it is a complementary mediation.

H5: When stress at workplace is held constant, there is also a direct negative effect of sleep deprivation on individual performance.

Result and Interpretation: H5 has also been accepted and proved that when the indirect effect of stress at workplace has been controlled, there is also a direct negative association between sleep deprivation and employee performance as the $p$ value is less than 0.05, ( $\mathrm{p}=.0015$, coefficient $=-0.3835)$ as shown in the Appendix B (see the results of Bootstrapping).

\section{CONCLUSION}

Sleepiness is specifically a state in which one is helpless and fails to remain completely conscious during a period that wakefulness is anticipated; while, weariness relates to a subjective absence of vitality of the mind and body. Both lessen attentiveness, which increases the likelihood of deterioration of your job-related and driving skills in this manner. Thus lack of sleep makes it hard to keep one's performance in a consistent and steady manner in the long run, as measured by reaction dormancy, reaction variability, speed, exactness, dexterity, choice making, and the ability to remember things.

Hence, it can be concluded based on the interpretation of results that relationship between sleep deprivation and employee performance is partially mediated by stress at workplace. Keeping social and organizational psychology in perspective, along with evidence from sleep research and neuroscience to establish and validate a hypothetically and empirically driven model of the effects of sleep deprivation on performance of working mothers was the main purpose of this study.

In areas such as customer service, involving customer feedback, where emotional 
stability is of utmost importance, sleep deprivation plays a vital role in such situations and hence it is proved that sleep deprived individuals need to have sufficient hours of sleep to perform well at work.

Sleep deprived employees are more likely to express frustration and irritation when dealing with complaints from cribbing clients. Managers need to ensure that their employees are not sleep deprived in order to escape such undesirable situations from occurring. Some organizational cultures are such where working late into the night is more than a requirement. These situations require instilling of habits like taking short power naps and training programs to teach the mind to understand the crucial importance of sleep in one's life, especially at the workplace.

Despite the utmost importance that the matter of sleep deprivation in the workplace deserves, and the fact that it has been a matter of growing concern, various studies related to it have been overlooked in the organizational literature. This research attempts to bring this matter into limelight so that steps can be taken towards finding a unanimous solution for declining performance of sleep deprived mothers at the workplace. I am hoping that my efforts would contribute positively in bringing into attention the possible effects of inadequate sleep on stress levels, workplace deviance, and, majorly, on the performance of working mothers. If present scenario continues, researches related to sleep deprivation will become more significant to understanding and consideration of employees' behaviors in a professional setting and will also provide a favorable opportunity and forum for the potential researches in future.

\subsection{Managerial Implications.}

The role of women has undergone a huge revolution in the corporate world and the different positions that they serve within the organization are many and varied. The increased interest of women in working in offices and working outside of home has led to the following concerns to be considered: (1) should mothers be given the freedom of stepping out of home, to embrace the role of a business woman? (2) and if yes, then who shall be responsible for the caretaking of their kids?

Mothers can afford to have a work-life balance if the management of their organization facilitates them in manner that they are able to categorically give time to both the office and her kids back at home. This way job satisfaction and workplace productivity will automatically increase. This would even entail an ideal solution for mothers who wish to further their careers along with taking care of home and kids. Certain rules, policies and procedures need to be formulated and executed in organizations so that working mothers can be empowered to owe their loyalty to their work and do justice back at home as well:

Paid maternity leaves are an effective way to financially aid women during their early motherhood along with a deep sense of gratitude for the organization, developing a desire to serve the organization longer and better. Being financially sound will upgrade her family's status making her satisfied and productive at work. Staff turnover will 
automatically drop down. Hence, it follows that mothers will be able to spend quality time with their young ones, catering to their new-born's needs as nurturing in early stages sets the individual to grow up healthy and happy. She will get time for breastfeeding and immunizations which will prevent future diseases, happy children means happy mothers and hence a happy employee. Fewer absences will be taken due to health issues.

An ardent step to reduce employee turnover and increase employee satisfaction and loyalty would be to provide flexible working hours, child-leaves and assistance for child-care along with convenient travelling option for babies. All these can serve as motivating factors for the mothers to perform better at work.

Paid sick leaves ensure that employees are able to take out time for themselves, even if it is taken annually. Working mothers if granted wit paid leaves to take care of their child's health issues will help her stay calm at office. Having the assurance that their abby is doing will certainly help them perform efficiently at both fronts. Also every child craves and demands attention and show positive signs of recovery when showered with their mother's love and attention. It is but, natural that employees (working mothers) productivity will be affected by all of the above factors. Employee retention has shown to rise when these factors were kept in mind and policies were made around it.

\subsection{Limitations and Suggestions for Future Research}

The struggle that has been made in order to explore the relationship between sleep deprivation and employee performance and to see whether "stress at workplace" mediates the given relationship or not, it went successful but still I faced few limitation which need to be discussed here which are as follows:

An in-depth analysis of the relationship between variables is necessary to understand the correlation more comprehensively. Despite the fact that the conclusions drawn and results that are evaluated from the current study support the theoretical framework, still a longitudinal design needs to be worked upon (Bollen, 1989). This research design method would enable us to get a more precise understanding of the whole scenario than the cross sectional design. The estimation of the extent to which sleep deprivation influences individual performance would then be determined more accurately. Due to some circumstantial constraints, cross sectional data was used in this study rather than a set of data in its longitudinal form; thus, it was unable to develop the causality more appropriately. Hence, in order to attain causality in future more aptly, this point should be kept in mind.

Self-reported questionnaire is the most commonly used medium in order to extract data regarding the research topic. Hence, it follows that it could succumb to major errors and the possibility that the responses recorded is unfair, being a major hindrance in the study. The service sector under study is characterized by proficiency and deliverance of maximum output and due to the factor of job insecurity and unpredictability being quite high in the environment, the subjects (employees) would opt to respond positively 
and favorably to the questionnaire in general and the major constructs of the study relating to sleep deprivation, stress levels and their overall performance. Thus, participants' inclination for giving impression to management may overstate the mean values of the constructs and may even affect the resulting data; thus, establishing the unnecessary intensity of the linkage between the variables that are dependent and independent.

For this study, employees are obviously the only source of data to analyze the different measures so any inefficiency/deficiency in that source may pollute all the measures and thus, give rise to imprecise results for the study. Therefore, in future, to mitigate the effects of any such discrepancy, it is suggested that the data to be surveyed should be taken from multiple sources.

On the other hand, all the given constructs have been measured based on certain perceptions, which proved to be deterrence in formulating desirable, accurate and valid results. It should therefore, be kept in mind that future researchers should aim to use measures which are objective based in order to gain more reliable and valid results.

The frequency of people who were willing to disclose honest opinion related to their organization and their work performance, were limited which resulted in the study being subject to skewed results and ultimately, the conclusion based on the given results could be hampered (Magnusson \& Bergman, 1990). In Pakistan as well as globally, such surveys do not receive much appreciation or acknowledgement. Therefore, a need has arisen to widen the base of respondents in future studies.

Another limitation of this research is implementation of non-probability sampling technique, which is the weakest form of sampling design. Kerlinger and Lee (2000) preferred and suggested to opt for this method only when no other option was available to obtain a sample. Generalizability can then only be established on the whole population with a certain level of care. Non-response bias is a problem that stems here. The theory of non-response bias suggests that the approach towards answering questionnaires varies greatly between those subjects who respond and those who do not respond personally to the survey. To limit the uncertainty of non-response bias, future researchers should select a technique from probability sampling design, making the results more comprehensive and representative of the entire population.

\section{REFERENCES}

Baldwin Jr, D. C., \& Daugherty, S. R. (2004). Sleep deprivation and fatigue in residency training: results of a national survey of first-and second-year residents.ÊSleep, $\hat{E} 27(2), 217-223$.

Barnett, K. J., \& Cooper, N. J. (2008). The effects of a poor night sleep on mood, cognitive, autonomic and electrophysiological measures. Journal of Integrative Neuroscience, 7: 405-420.

Beehr, T. A., Jex, S. M., Stacy, B. A., \& Murray, M. A. (2000). Work stressors and coworker support as predictors of individual strain and job performance. Journal 
of Organizational Behavior, 21(4), 391-405.

Bennett, R. J., \& Robinson, S. L. (2000). Development of a measure of workplace deviance.ÊJJournal of applied psychology,Ê85(3), 349.

Black, T.R. (1999). Doing quantitative research in the social sciences: an integrated approach to research design, measurement, and statistics. London: Sage.

Bollen, K. A. (1989). Structural equations with latent variables. New York:Wiley.

Carskadon, M. A. (1990). Patterns of sleep and sleepiness in adolescents. Pediatrician, 17(1), 5-12.

Chen, J. H., Gill, T. M., \& Prigerson, H. G. (2005). Health behaviors associated with better quality of life for older bereaved persons.ÊJournal of palliative medicine,Ê8(1), 96-106.

Cohen, S. (1980). Aftereffects of stress on human performance and social behavior: a review of research and theory. Psychological bulletin, 88(1), 82.

Comrey, AL \& Lee, HB. (1992), A first course in factor analysis, 2 ed. nd L Erlbaum Associates, New Jersey.

Cronbach, L. J. (1951). Coefficient alpha and the internal structure of tests. Psychometrika. $16,297-334$.

Fredriksen, K., Rhodes, J., Reddy, R., \& Way, N. (2004). Sleepless in Chicago: tracking the effects of adolescent sleep loss during the middle school years. Child development, 75(1), 84-95.

Gangwisch, J. E., Malaspina, D., Boden-Albala, B., \& Heymsfield, S. B. (2005). Inadequate sleep as a risk factor for obesity: analyses of the NHANES I.SLEEPNEW YORK THEN WESTCHESTER-,E28(10), 1289.

Glass, D. C., \& Singer, J. E. (1972). Urban stress: Experiments on noise and social stressors.

Hair, JF, Anderson, RE, Tatham, RL \& Black, WC (1995). Multivariate data analysis with readings, 4th edn. Prentice-Hall International, Englewood Cliffs, pp.274.

Harrold, R., \& Wayland, M. (2002). New methods to reduce workplace stress. Industrial Concepts, 19-21.

Hasler, G., Buysse, D. J., Gamma, A., Ajdacic, V., Eich, D., Rossler, W., \& Angst, J. (2005). Excessive daytime sleepiness in young adults: a 20 -year prospective community study. Journal of Clinical Psychiatry, 66(4), 521-529. 
The Effects of Sleep Deprivation on the Job Performance of Working Mothers

House, R. J., \& Rizzo, J. R. (1972). Role conflict and ambiguity as critical variables in a model of organizational behavior.ÊOrganizational behavior and human performance, $\hat{E} 7(3), 467-505$.

Ivancevich M.J., \& Donnelly H. J. (1975). Relation of Organizational Structure to job Satisfaction, Anxiety-Stress, and Performance. Administrative Science Quartely, Vol. 20, No. 2, pp. 272-280.

Jamal, M. (1984). Job stress and job performance controversy: An empirical assessment. Organizational behavior and human performance, 33(1), 1-21.

Kerlinger, F. N., \& Lee, H. B. (2000). Foundations of behavioral research (4 ed.). Orlando, FL: Harcourt College Publishers.

Kripke, D. F., Garfinkel, L., Wingard, D. L., Klauber, M. R., \& Marler, M. R. (2002). Mortality associated with sleep duration and insomnia.ÊArchives of general psychiatry, $\hat{E} 59(2), 131-136$.

Lazarus, R. S., Deese, J., \& Osler, S. F. (1952). The effects of psychological stress upon performance. Psychological Bulletin, 49(4), 293.

Magnusson, D., \& Bergman, L. R. (Eds.). (1990).ÊData quality in longitudinal researchÊ(Vol. 3). Cambridge University Press.

Morrison, D. N., McGEE, R. O. B., \& Stanton, W. R. (1992). Sleep problems in adolescence. Journal of the American Academy of Child \& Adolescent Psychiatry, 31(1), 94-99.

Mouton, J. \& Marais, H.C. (1990) Basic concepts in the methodology of the social sciences; Rev. ed. Pretoria: Human Sciences Research Council.

National Institute for Occupational Safety and Health. 2004. Overtime and extended work shifts: Recent findings on illnesses, injuries, and health behaviors. Publication 2004-143. Cincinnati: National Institute for Occupational Safety and Health.

Pallant, J. (2001). SPSS survival manual: a step by step to data analysis using SPSS, Allen \& Unwin, Australia.

Pilcher, J. J., \& Huffcutt, A. J. (1996). Effects of sleep deprivation on performance: a meta-analysis.ÊSleep: Journal of Sleep Research \& Sleep Medicine, 19(4):318326.

Podsakoff, P. M., \& MacKenzie, S. B. (1989). A second generation measure of organizational citizenship behavior. Unpublished manuscript, Indiana Univer- 
sity, Bloomington.

Sleep and Mood (http://healthysleep.med.harvard.edu/need-sleep/whats-in-it-foryou/mood).

Sleep Deficit: The Performance Killer (https://hbr.org/2006/10/sleep-deficit-theperformance-killer).

Sleep Deprivation and New Parents

(http://consumer.healthday.com/encyclopedia/parenting-31/parenting-healthnews-525/sleep-deprivation-and-new-parents-643886.html).

Sleep Deprivation and Stress (http://consumer.healthday.com/encyclopedia/stressmanagement-37/stress-health-news-640/sleep-deprivation-and-stress646063.html).

Sleep Deprivation Linked to Inappropriate, Unethical Behavior on The job (http://www.psychologicalscience.org/index.php/news/minds-business/sleepdeprivation-linked-to-inappropriate-unethical-behavior-on-the-job.html).

Sleep Deprivation Makes You Work Slower: Study (http://www.huffingtonpost.com/2012/07/30/sleep-deprivation-work-slowerproductivity-speed_n_1720700.html).

Sleep deprivation may be undermining teen health (http://www.apa.org/monitor/oct01/sleepteen.aspx).

Sleep Deprivation's True Workplace Costs (https://hbr.org/2011/01/sleep-deprivationstrue-workpl.html).

Sleep Disruption a key Factor in Anxiety Disorders (http://www.medscape.com/viewarticle/807404).

Sleep study shows new moms are dangerously exhausted for months (http://www.pbs.org/newshour/rundown/sleep-study-shows-new-momsdangerously-exhausted-months/).

Sleep, Performance, and Public Safety (http://healthysleep.med.harvard.edu/healthy/ matters/consequences/sleep-performance-and-public-safety).

Strine, T. W., \& Chapman, D. P. (2005). Associations of frequent sleep insufficiency with health-related quality of life and health behaviors. Sleep medicine, 6(1), 23-27.

Van Yperen, N. W., \& De Jong, I. J. A. (1997). Is een tevreden werknemer ook een productieve werkne-mer? [Is a satisfied employee also a productive em-ployee?]. Gedrag en Organisatie, 10: 69-77. 


\section{Appendix A (Tables)}

Table 4.1: Mean, SD and Skewness of All Variables (N=377)

\begin{tabular}{|l|l|l|l|l|}
\hline \multirow{2}{*}{ SD } & Workplace Deviance & $\begin{array}{l}\text { Stress } \\
\text { workplace }\end{array}$ & $\begin{array}{l}\text { at } \\
\text { Perfoyee } \\
\text { Permance }\end{array}$ \\
\hline \multirow{5}{*}{$\begin{array}{l}\text { Not Sleep } \\
\text { Deprived }\end{array}$} & N & 64.00 & 64.00 & 64.00 \\
\cline { 2 - 5 } & Mean & 2.93 & 3.48 & 3.40 \\
\cline { 2 - 5 } & Std. Error of Mean & 0.08 & 0.07 & 0.10 \\
\cline { 2 - 5 } & Median & 2.93 & 3.71 & 3.40 \\
\cline { 2 - 5 } & Mode & 2.71 & 3.71 & 3.40 \\
\cline { 2 - 5 } & Standard Deviation & 0.63 & 0.56 & 0.83 \\
\cline { 2 - 5 } & Skewness & -0.17 & -1.17 & -0.06 \\
\cline { 2 - 5 } & Std. Error of Skewness & 0.30 & 0.30 & 0.30 \\
\cline { 2 - 5 } & Kurtosis & -0.13 & 1.78 & -0.54 \\
\cline { 2 - 5 } & Std. Error of Kurtosis & 0.59 & 0.59 & 0.59 \\
\cline { 2 - 5 } & Minimum & 1.43 & 2.00 & 2.00 \\
\cline { 2 - 5 } & Maximum & 4.00 & 4.71 & 4.80 \\
\hline \multirow{5}{*}{ Sleep Deprived } & 276.00 & 276.00 & 276.00 \\
\cline { 2 - 5 } & Mean & 3.56 & 3.88 & 2.55 \\
\cline { 2 - 5 } & Std. Error of Mean & 0.03 & 0.03 & 0.05 \\
\cline { 2 - 5 } & Median & 3.71 & 4.00 & 2.60 \\
\cline { 2 - 5 } & Mode & 4.00 & 4.00 & 2.00 \\
\cline { 2 - 5 } & Standard Deviation & 0.57 & 0.45 & 0.89 \\
\cline { 2 - 5 } & Std. Error of Skewness & -0.93 & -0.74 & 0.23 \\
\cline { 2 - 5 } & Kurtosis & 0.84 & 0.15 & 0.15 \\
\cline { 2 - 5 } & Std. Error of Kurtosis & 0.29 & 1.36 & 0.29 \\
\cline { 2 - 5 } & Minimum & 1.43 & 2.43 & 1.00 \\
\cline { 2 - 5 } & Maximum & 5.00 & 5.00 & 5.00 \\
\hline
\end{tabular}

Table 4.2: Correlation Matrix of Study Variables $(\mathrm{N}=340)$

\begin{tabular}{|l|l|l|l|l|}
\hline Variable & $\mathbf{1}$ & $\mathbf{2}$ & $\mathbf{3}$ & $\mathbf{4}$ \\
\hline 1- Sleep Deprivation & - & & & \\
\hline 2- Workplace Deviance & $.386^{* *}$ & - & & \\
\hline 3- Stress at workplace & $.319^{* *}$ & $.453^{* *}$ & - & \\
\hline 4- Employee Performance & $-.354^{* *}$ & $-.475^{* *}$ & $-.430^{* *}$ & \\
\hline
\end{tabular}

Sleep deprivation was coded 0 , “no sleep deprivation," or 1 , “total sleep deprivation.” $\mathrm{N}=377$, $* * \mathrm{p}<0.01, * \mathrm{p}<0.05$. 
Table 4.3: Alpha Reliability Coefficients of Composite Scales (N=340)

\begin{tabular}{|l|l|l|}
\hline Variable Name & No. of Items & $\begin{array}{l}\text { Cronbach's Alpha } \\
\text { Coefficient }\end{array}$ \\
\hline Workplace Deviance & 7 & 0.849 \\
\hline Workplace Stress & 7 & 0.773 \\
\hline Individual Performance & 5 & 0.913 \\
\hline
\end{tabular}

Table 4.4: Mediation of the Effect of Sleep Deprivation on Employee Performance through Stress at workplace (Point estimates and BC 95\% CI for Indirect effects)

\begin{tabular}{|c|c|c|c|c|c|c|c|c|c|}
\hline \multirow{3}{*}{ Variables } & \multirow{3}{*}{$\begin{array}{l}\text { Point } \\
\text { Estimates }\end{array}$} & \multirow{2}{*}{\multicolumn{2}{|c|}{$\begin{array}{l}\text { Product of } \\
\text { Coefficients }\end{array}$}} & \multicolumn{2}{|c|}{ Bootstrapping } & & & & \\
\hline & & & & \multicolumn{2}{|c|}{ BCa $95 \%$ CI } & \multicolumn{2}{|c|}{$\begin{array}{l}\text { Percentile } 95 \% \\
\text { CI }\end{array}$} & \multicolumn{2}{|c|}{ BC $95 \% \mathrm{CI}$} \\
\hline & & SE & $\mathbf{Z}$ & Lower & Upper & Lower & Upper & Lower & Upper \\
\hline $\begin{array}{l}\text { Mean_S } \\
\text { W }\end{array}$ & -.1843 & .0494 & -3.7305 & -.3062 & -.0928 & -.3045 &.-0887 & -.3087 & -.0927 \\
\hline Total & -.4652 & .0744 & 6.2551 & -.6366 & -.3218 & -.6244 & -.3186 & -.6373 & -.3284 \\
\hline
\end{tabular}

Note: $* \mathrm{BCa}=$ corrections for both median bias and skew have been included in the bias corrected and accelerated bootstrapping confidence intervals. Zero confidence intervals are interpreted as not: 5,000 bootstrap samples.

Table 4.5: Hypothesis Assessment Summary

\begin{tabular}{|l|l|l|l|}
\hline S.No. & Hypothesis & $\begin{array}{l}\text { Testing } \\
\text { Specifications }\end{array}$ & $\begin{array}{l}\text { Empirical } \\
\text { conclusion }\end{array}$ \\
\hline $\mathbf{0 1}$ & $\begin{array}{l}\text { H1: There is a negative association between sleep deprivation } \\
\text { and individual performance (path c). }\end{array}$ & 0.0000 & Accepted \\
\hline $\mathbf{0 2}$ & $\begin{array}{l}\text { H2: There is a positive relationship between sleep deprivation } \\
\text { and stress at workplace (path } \mathrm{a}_{2} \text { ). }\end{array}$ & 0.0000 & Accepted \\
\hline $\mathbf{0 3}$ & $\begin{array}{l}\text { H3: There is a negative relationship between stress at } \\
\text { workplace and employee performance (path } \mathrm{b}_{2} \text { ). }\end{array}$ & 0.0000 & Accepted \\
\hline $\mathbf{0 4}$ & $\begin{array}{l}\text { H4: Stress at workplace mediates the relationship between } \\
\text { sleep deprivation and individual performance. }\end{array}$ & 0.0000 & Accepted \\
\hline $\mathbf{0 5}$ & $\begin{array}{l}\text { H5: When stress at workplace is held constant, there is also a } \\
\text { direct negative effect of sleep deprivation on individual } \\
\text { performance (path c prime). }\end{array}$ & 0015 & Accepted \\
\hline
\end{tabular}


The Effects of Sleep Deprivation on the Job Performance of Working Mothers

\section{Appendix B (SPSS Macro Input and Output)}

Run MATRIX procedure:

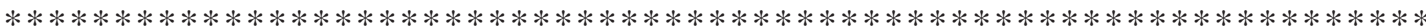

Preacher And Hayes (2008) SPSS Macro For Multiple Mediation

Written by Andrew F. Hayes, The Ohio State University

http://www.comm.ohio-state.edu/ahayes/

For details, see Preacher, K. J., \& Hayes, A. F. (2008). Asymptotic

and resampling strategies For assessing And comparing indirecct effects in multiple mediator models. Behavior Research Methods, 40, 879-891

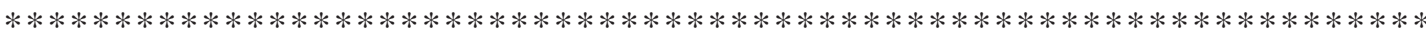

Dependent, Independent, and Proposed Mediator Variables:

DV = Mean_EP

$\mathrm{IV} \quad=\mathrm{SD}$

MEDS = Mean_WD

Mean_SW

Sample size

340

IV to Mediators (paths)

$\begin{array}{lcccc} & \text { Coeff } & \text { se } & \mathrm{t} & \mathrm{p} \\ \text { Mean_WD } & .6229 & .0810 & 7.6902 & .0000 \\ \text { Mean_SW } & .4060 & .0655 & 6.1958 & .0000\end{array}$

Direct Effects of Mediators on DV (b paths)

$\begin{array}{lllcc} & \text { Coeff } & \mathrm{se} & \mathrm{t} & \mathrm{p} \\ \text { Mean_WD } & -.4510 & .0790 & -5.7063 & .0000 \\ \text { Mean_SW } & -.4540 & .0977 & -4.6477 & .0000\end{array}$

Total Effect of IV on DV (c path)

Coeff se t p

$\begin{array}{lllll}\text { SD } & -.8488 & .1219 & -6.9649 & .0000\end{array}$

Direct Effect of IV on DV (c-prime path)

Coeff se t $\mathrm{p}$

$\begin{array}{lllll}\text { SD } & -.3835 & .1200 & -3.1954 & .0015\end{array}$

Model Summary for DV Model

$\begin{array}{llllll}\text { R-sq } & \text { Adj R-sq } & \text { F } & \text { df1 } & \text { df2 } & \text { p } \\ .3044 & .2982 & 49.0162 & 3.0000 & 336.0000 & .0000\end{array}$

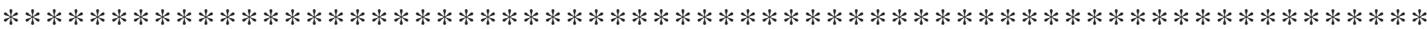




\section{NORMAL THEORY TESTS FOR INDIRECT EFFECTS}

Indirect Effects of IV on DV through Proposed Mediators (ab paths)

$\begin{array}{lllll}\text { Effect } & \text { se } & \mathrm{Z} & \mathrm{p} & \\ & -.4652 & .0744 & -6.2551 & .0000\end{array}$

$\begin{array}{lllll}\text { TOTAL } & -.4652 & .0744 & -6.2551 & .0000 \\ \text { Mean WD } & -.2809 & .0611 & -4.5981 & .0000\end{array}$

Mean_SW $\quad-.1843 \quad .0494 \quad-3.7305 \quad .0002$

\section{BOOTSTRAP RESULTS FOR INDIRECT EFFECTS}

Indirect Effects of IV on DV through Proposed Mediators (ab paths)

Data boot Bias SE

$\begin{array}{lllll}\text { TOTAL } & -.4652 & -.4651 & .0001 & .0790\end{array}$

$\begin{array}{lllll}\text { Mean_WD } & -.2809 & -.2799 & .0010 & .0660\end{array}$

Mean_SW $\quad-.1843 \quad-.1852 \quad-.0009 \quad .0543$

Bias Corrected Confidence Intervals

Lower Upper

TOTAL $\quad-.6373-.3284$

Mean_WD $\quad-.4345 \quad-.1702$

Mean_SW $\quad-.3087 \quad-.0927$

Percentile Confidence Intervals

Lower Upper

TOTAL $\quad-.6244 \quad-.3186$

Mean_WD $\quad-.4140 \quad-.1612$

Mean_SW $\quad-.3045 \quad-.0887$

Bias Corrected and Accelerated Confidence Intervals

$\begin{array}{lcc} & \text { Lower } & \text { Upper } \\ \text { TOTAL } & -.6366 & -.3218 \\ \text { Mean_WD } & -.4361 & -.1645 \\ \text { Mean_SW } & -.3062 & -.0928\end{array}$

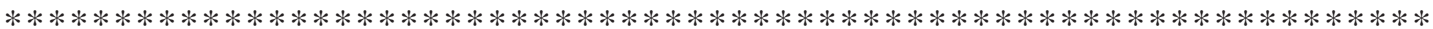

Level of Confidence for Confidence Intervals:

95

Number of Bootstrap Resamples:

5000 